\title{
Phospholipid chlorohydrins cause ATP depletion and toxicity in human myeloid cells
}

\author{
Gary Dever ${ }^{\mathrm{a}}$, Laura-Jayne Stewart ${ }^{\mathrm{a}}$, Andrew R. Pitt ${ }^{\mathrm{b}}$, Corinne M. Spickett ${ }^{\mathrm{a}, *}$ \\ ${ }^{a}$ Department of Bioscience, University of Strathclyde, 204 George Street, Glasgow G1 1XW, UK \\ ${ }^{\mathrm{b}}$ Department of Pure and Applied Chemistry, University of Strathclyde, 295 Cathedral Street, Glasgow G1 $1 X L, U K$
}

Received 18 February 2003; accepted 22 February 2003

First published online 21 March 2003

Edited by Barry Halliwell

\begin{abstract}
Chlorohydrins of stearoyl-oleoyl phosphatidylcholine (SOPC), stearoyl-linoleoyl phosphatidylcholine, and stearoylarachidonyl phosphatidylcholine were incubated with cultured myeloid cells (HL60) for $24 \mathrm{~h}$, and the cellular ATP level was measured using a bioluminescent assay. The chlorohydrins caused significant depletion of cellular ATP in the range 10$100 \mu \mathrm{M}$. The ATP depletion by the phospholipid chlorohydrins was slightly less than that of 4-hydroxy-2-nonenal, but greater than that of hexanal, trans-2-nonenal, and autoxidised palmitoyl-arachidonoyl phosphatidylcholine. SOPC chlorohydrin was also found to cause loss of viability in U937 cells, and thus phospholipid chlorohydrins could contribute to the formation of a necrotic core in advanced atherosclerotic lesions.

(C) 2003 Published by Elsevier Science B.V. on behalf of the Federation of European Biochemical Societies.
\end{abstract}

Key words: Phosphatidylcholine; $\mathrm{HOCl}$; Oxidative stress; Chlorohydrin; HL60; Atherosclerosis

\section{Introduction}

Atherosclerosis is now increasingly regarded as an inflammatory condition, in which immune cells play a significant role [1]. It is also well established that the oxidation of low density lipoprotein (LDL) is a key risk factor for atherosclerosis [2], and that oxidised LDL (oxLDL) can contribute to the disease pathology via several different mechanisms. There is evidence that oxLDL has many biological effects including cytotoxicity, proliferation of smooth muscle cells and monocytes, binding of monocytes to the endothelium, stimulation of cytokine release and interference with endothelium-mediated relaxation $[3,4]$.

In view of the pro-inflammatory and pro-atherogenic effects of oxLDL, it is important to define the precise components of oxLDL which may be responsible for some or all of these effects. Peroxidation of polyunsaturated LDL lipids has long been an area of interest, as it is well established that the

*Corresponding author. Fax: (44)-141-553 4124.

E-mail address: c.m.spickett@strath.ac.uk (C.M. Spickett).

Abbreviations: DMSO, dimethylsulfoxide; ESMS, electrospray mass spectrometry; HBSS, Hanks-buffered saline solution; HNE, 4-hydroxy-2-trans-nonenal; oxLDL, oxidised low density lipoprotein; PAPC, palmitoyl-arachidonoyl phosphatidylcholine; SAPC, stearoylarachidonoyl phosphatidylcholine; SLPC, stearoyl-linoleoyl phosphatidylcholine; SOPC, stearoyl-oleoyl phosphatidylcholine aldehyde breakdown products of lipid peroxides have a variety of deleterious effects in biological systems. Malondialdehyde, a commonly measured marker of lipid peroxidation, reacts readily with several protein sidechain groups, causing loss of protein function [5]. Another lipid peroxidation product, 4-hydroxynonenal (HNE), has been found to be cytotoxic and bioactive through a wide variety of different mechanisms, as reviewed recently by Poli and Schaur [6].

More recently, interest has developed in hypochlorous acid $(\mathrm{HOCl})$ as a potential oxidant of LDL in vivo. $\mathrm{HOCl}$ is produced by the enzyme myeloperoxidase [7], which is present in monocytes and at high levels in neutrophils. There is mounting evidence for the involvement of myeloperoxidase and $\mathrm{HOCl}$ in atherosclerosis; myeloperoxidase has been detected in an active form in atherosclerotic lesions [8], and $\mathrm{HOCl}-$ modified epitopes of LDL have been detected in lesions using a specific monoclonal antibody [9]. Chlorotyrosine derivatives have been detected at all stages of lesion development and are elevated in LDL from atherosclerotic intima [10]. Moreover, it has been found that HOCl-modified LDL can induce interleukin-8 expression and cause chemotactic migration of neutrophils [11]. $\mathrm{HOCl}$ can react with unsaturated fatty acids to form chlorohydrins [12], and it has been reported that chlorohydrins and bromohydrins of oleic acid are toxic to endothelial cells, causing lysis and necrotic cell death [13]. Treatment of isolated human LDL with either $\mathrm{HOCl}$ or myeloperoxidase, at concentrations similar to those thought to occur in atherosclerotic lesions, results in generation of phospholipid chlorohydrins [14], and therefore it is also important to determine the biological effects of these compounds, in order to understand their potential contribution to atherosclerotic progression. In this study, we have prepared specific phosphatidylcholine chlorohydrins, and examined their ability to deplete cellular ATP in cultured human myeloid cells, in comparison with the aldehydes hexanal, 2-transnonenal and HNE, and autoxidised palmitoyl-arachidonoyl phosphatidylcholine (PAPC). The toxicity of SOPC chlorohydrin was also compared with that of HNE. This is the first report of the cellular effects of chlorinated derivatives of phospholipids.

\section{Materials and methods}

\subsection{Preparation of chlorohydrins}

All phospholipids were purchased from Sigma. Stearoyl-oleoyl phosphatidylcholine (SOPC), stearoyl-linoleoyl phosphatidylcholine (SLPC), stearoyl-arachidonoyl phosphatidylcholine (SAPC), and PAPC were prepared individually in chloroform at a concentration of $10 \mathrm{mg} / \mathrm{ml}$. Aliquots of each lipid were dried under nitrogen and 
reconstituted by whirlimixing in an equal volume of Hanks-buffered saline solution (HBSS), followed by sonication at $35^{\circ} \mathrm{C}$ for $15 \mathrm{~min}$, to form lipid vesicles. The vesicles were treated with a 10 -fold molar excess of sodium hypochlorite at $\mathrm{pH} 6.0$ until approximately complete conversion of the native phospholipid was achieved (between 15 and $50 \mathrm{~min}$, depending on the lipid used). Excess hypochlorite was removed by passing the incubation mixture through a Sep-pak cartridge (Waters, UK) and eluting the phospholipid with 1:1 methanol:chloroform followed by $100 \%$ chloroform. The organic solvent was removed under a stream of nitrogen and the phospholipid chlorohydrins were reconstituted in HBSS and filtered through a 0.2 micron gamma-sterilised filter prior to addition to the cells.

\subsection{Analysis of chlorohydrins and autoxidised PAPC}

The conversion of native lipids to chlorohydrins was monitored following the reaction period and after elution from the Sep-pak column by electrospray mass spectrometry (ESMS). One $\mu$ l aliquots were removed and diluted 200-fold with 71:5:7 (v/v/v) methanol:hexane:0.1 M ammonium acetate. ESMS was carried out on Platform (VG) or LCQ-Duo (Finnigan) mass spectrometers in positive ion mode by direct infusion. A spectrum in the range $400-1050 \mathrm{~m} / \mathrm{z}$ was obtained, and both loss of the native lipids and appearance of chlorohydrins at multiples of $+52 /+54 \mathrm{~m} / \mathrm{z}$ were monitored as described previously [14].

A $50 \mu \mathrm{l}$ aliquot of PAPC $(10 \mathrm{mg} / \mathrm{ml}$ in chloroform $)$ was dried under nitrogen and allowed to autoxidise in the dark at $40^{\circ} \mathrm{C}$ for $100 \mathrm{~h}$. The lipid was reconstituted in $50 \mu \mathrm{l}$ of chloroform and diluted 200 -fold in ESMS running solvent. Spectra were collected on an LCQ-Duo between 400 and $1100 \mathrm{~m} / \mathrm{z}$ to obtain a profile of the autoxidation products.

\subsection{Preparation of aldehydes}

Hexanal and trans-2-nonenal were prepared in UHP water, and HNE was prepared in ethanol, to give stock solutions of $100 \mathrm{mM}$ which were sterilised by filtration at 0.2 micron. The quality of an aqueous dilution of the HNE preparation was checked by UV absorbance for the occurrence of a single maximum at $223 \mathrm{~nm}$, and the concentration was confirmed using $\varepsilon=13750 \mathrm{M}^{-1} \mathrm{~cm}^{-1}$. Further dilutions to two times the final required concentrations of the aldehydes were made in RPMI-1640 medium using sterile procedures.

\subsection{Cell culture and treatment}

HL60 and U937 cell lines (ECACC) were cultured at $37^{\circ} \mathrm{C}$ in RPMI-1640 medium containing $2 \mathrm{mM}$ L-glutamine and $25 \mathrm{mM}$ HEPES, and supplemented with $10 \%$ foetal calf serum. Some experiments were also carried out in medium containing low levels of foetal calf serum $(0.5 \%)$. Treatment with the test compounds was carried out in 96-well luminescence plates (Greiner, UK), with $1 \times 10^{4}$ cells per well (100 $\mu \mathrm{l}$ volume). Aliquots $(100 \mu \mathrm{l})$ of the sterile chlorohydrin or aldehyde preparations were added to wells, and the plate was incubated at $37^{\circ} \mathrm{C}$ in a humidified atmosphere with $95 \% \mathrm{O}_{2}$ and $5 \% \mathrm{CO}_{2}$ for $24 \mathrm{~h}$. The treatment concentrations used were $0,10,25,50,100,150$ and $200 \mu \mathrm{M}$ for both phospholipid chlorohydrins and aldehydes. Additionally for the phospholipids, a set of control incubations were carried out with the native lipids at the same concentrations.

A $24 \mathrm{~h}$ timecourse was carried out with U937 cells incubated with $100 \mu \mathrm{M}$ SOPC chlorohydrin. Samples from the 96 -well culture plate were removed and analysed at $0,2,4,6,8,22$ and $24 \mathrm{~h}$.

\subsection{Analysis of cellular ATP levels}

Following incubation with the test compounds, the cellular ATP concentration was determined by the CellTitre-GloTM Luminescence assay (Promega, UK), which measures the intracellular ATP level using the ATP-dependent luciferin-luciferase reaction. The assay was performed according to the manufacturer's instructions, before recording the luminescence on a LUMIstar Galaxy Luminometer (BMG Labtechnologies, Aylesbury, UK). The integration time per well was $3 \mathrm{~s}$ and the gain was set at 100 . The luminescence was recorded as relative light units per second, and the results are expressed as a $\%$ of control ATP, to allow comparison between individual experiments.

\subsection{Analysis of viability by the MTT assay}

U937 cell treatments with SOPC chlorohydrin and HNE (concen- trations indicated in Fig. 6) were carried out as described in Section 2.4 but using $1 \times 10^{5}$ cells per well. After $24 \mathrm{~h}$ incubation, $10 \mu \mathrm{l}$ of sterile $10 \mathrm{mg} / \mathrm{ml}$ MTT solution (3-[4,5-dimethylthiazol-2-yl]-2,5-diphenyltetrazolium bromide) dissolved in RPMI-1640 medium (without phenol red) was added to the wells, and the plate was incubated for $90 \mathrm{~min}$ at $37^{\circ} \mathrm{C}$. The plate was centrifuged for $10 \mathrm{~min}$ at $600 \times \mathrm{g}$, the supernatant was removed and $200 \mu \mathrm{l}$ of $3: 1$ dimethylsulfoxide (DMSO):isopropanol (v/v) was added to each well. The plate was shaken for $15 \mathrm{~min}$ before reading the absorbance at $540 \mathrm{~nm}$ in a Labsystems iEMS Reader.

\section{Results}

The effect of three aldehydes, hexanal, trans-2-nonenal and HNE, on the human myeloid cell line HL60 was tested to provide a standard against which the phospholipid chlorohydrins could be compared, as aldehydes are already known to have various biological effects on many cells, including toxicity, and HNE in particular has been much studied [6]. Fig. 1 shows that hexanal had very little effect on the cells, with the only significant decrease in ATP concentration occurring with the $200 \mu \mathrm{M}$ treatment, where the [ATP] was found to be $90 \%$ of the control $(P<0.01)$. The response of the cells to trans-2nonenal was similar, with a significant decrease in [ATP] also
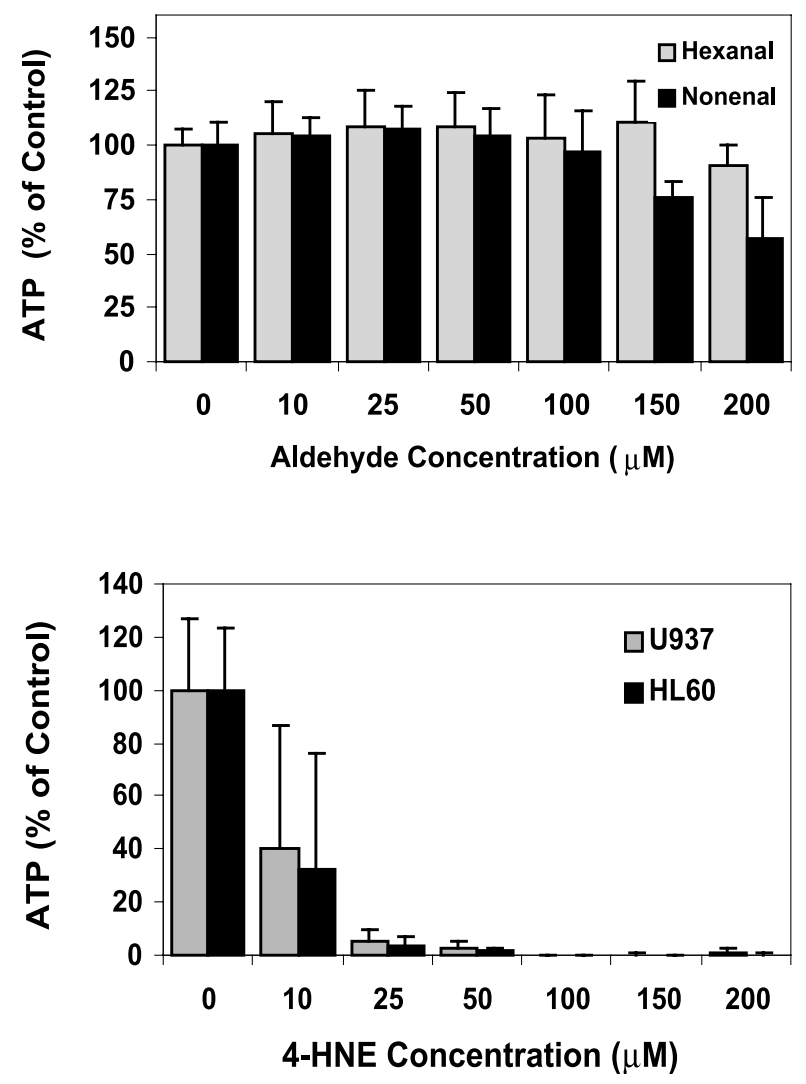

Fig. 1. The effect of aldehydes on cellular ATP in HL60 and U937 cells. Cells were incubated for $24 \mathrm{~h}$ in RPMI-1640 medium containing aldehydes at the concentrations indicated in the graphs. Following treatment, the cellular ATP level of the cells was determined using luciferin-luciferase in a bioluminescent assay, and the \% ATP level of the cells was calculated by comparison with untreated cells. The top graph shows the effect of hexanal and trans-2-nonenal on HL60 cells, and the bottom graph shows the effect of HNE on U937 and HL60 cells. The data are the average of three separate experiments each carried out in triplicate, and the error bars correspond to 1 S.D. 
only observed at $200 \mu \mathrm{M}(P<0.01)$, although the loss of ATP that occurred was greater, as the cells contained approximately $60 \%$ compared to the control. In contrast, HNE was found to have a much more severe effect, with $10 \mu \mathrm{M}$ already causing a substantial reduction in ATP levels in HL60 cells to $40 \%$ of the control value, and concentrations of $25 \mu \mathrm{M}$ and higher resulting in almost complete loss of ATP. The response
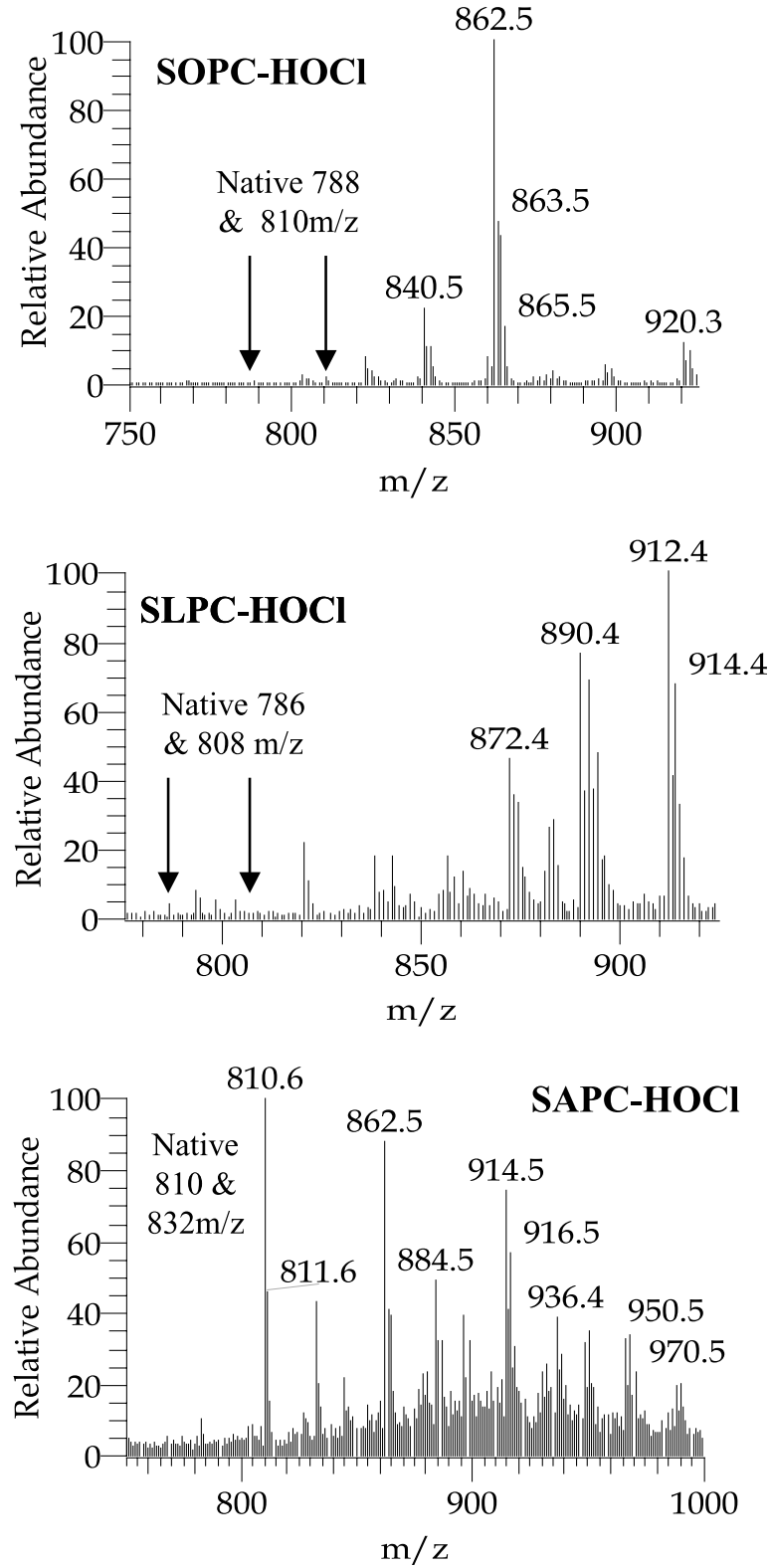

Fig. 2. Conversion of phospholipids to chlorohydrin products. The formation of chlorohydrins was monitored using ESMS for each of the phospholipids tested. Top spectrum: SOPC treatment with native lipid at $788 \mathrm{~m} / z\left(\mathrm{M}-\mathrm{H}^{+}\right.$ion) and $810 \mathrm{~m} / z$ (M-Na+ $\mathrm{Nan}^{+}$, monochlorohydrins at $840 \mathrm{~m} / \mathrm{z}\left(\mathrm{M}-\mathrm{H}^{+}\right.$ion) and $862 \mathrm{~m} / \mathrm{z}\left(\mathrm{M}-\mathrm{Na}^{+}\right.$ion). Middle spectrum: SLPC treatment with native lipid at $786 \mathrm{~m} / z$ (M$\mathrm{H}^{+}$ion) and $808 \mathrm{~m} / \mathrm{z}\left(\mathrm{M}-\mathrm{Na}^{+}\right.$ion), bis-chlorohydrins at $890 \mathrm{~m} / \mathrm{z}$ $\left(\mathrm{M}-\mathrm{H}^{+}\right.$ion) and $912 \mathrm{~m} / \mathrm{z}\left(\mathrm{M}-\mathrm{Na}^{+}\right.$ion). The signal at $872 \mathrm{~m} / \mathrm{z}$ appears to be an in-source dehydration product of the chlorohydrin, not a glycol, as it demonstrates a typical ${ }^{37} \mathrm{Cl}$-isotope pattern. Bottom spectrum: SAPC treatment with native lipid at $810 \mathrm{~m} / \mathrm{z}$ and $832 \mathrm{~m} / \mathrm{z}$, mono-chlorohydrin forms at 862 and $884 \mathrm{~m} / \mathrm{z}$, bis-chlorohydrin forms at 914 and $936 \mathrm{~m} / z$, and tris-chlorohydrin forms at 968 and $990 \mathrm{~m} / \mathrm{z}$.
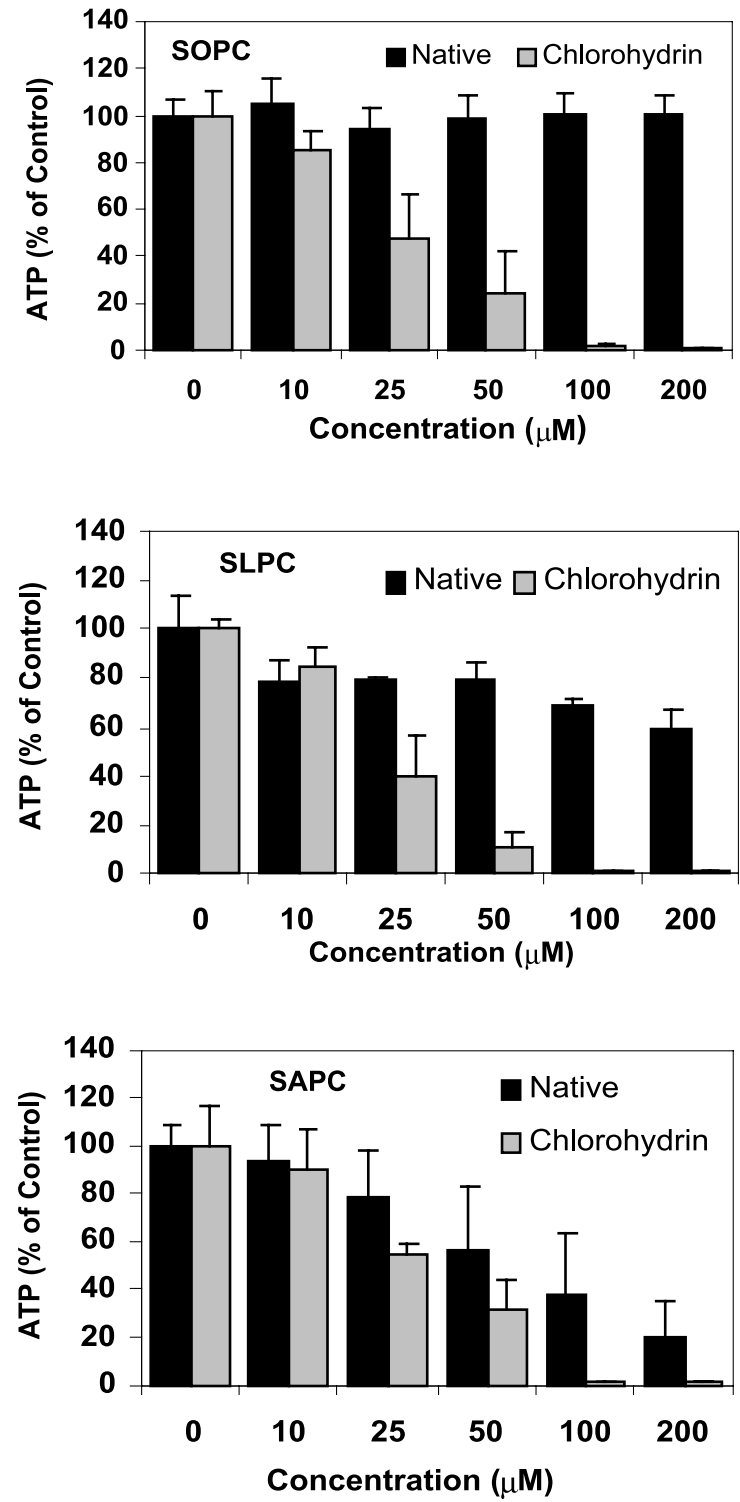

Fig. 3. The effect of phospholipid chlorohydrins on HL60 cell ATP levels. Cells were incubated for $24 \mathrm{~h}$ in RPMI-1640 medium containing the phospholipid chlorohydrins at the concentrations indicated in the graphs, and subsequently the cellular ATP level was determined as described in Fig. 1. In each graph the effect of the native (unoxidised) lipid was compared with that of the chlorohydrin: SOPC (top), SLPC (middle), and SAPC (bottom). The data are the average of three separate experiments each carried out in triplicate, and the error bars correspond to 1 S.D.

of U937 cells to HNE almost exactly paralleled that of the HL60 cells.

The effect of native phospholipids and the phospholipid chlorohydrins on HL60 cells was then investigated. The conversion of the native phospholipids was monitored by ESMS and representative spectra showing the composition of the chlorohydrin preparations are shown in Fig. 2. Treatment of SOPC and SLPC resulted in almost complete conversion to the chlorohydrin forms, and for SLPC the bis-chlorohydrin predominated. The conversion of SAPC to chlorohydrins was less complete, with about $40-50 \%$ conversion typically achieved, and mono-, bis-, and tris-chlorohydrins were all observed. In initial experiments, the cells were assessed after 
the $24 \mathrm{~h}$ incubation by staining with trypan blue, but no significant differences between chlorohydrin-treated and control cells were found. Subsequently, a bioluminescent method that uses luciferin and luciferase to detect cytosolic ATP was tested, as this has been reported to offer a sensitive method for monitoring viability [15].

Following treatment of the cells with chlorohydrins or native lipids for $24 \mathrm{~h}$, the cytosolic ATP levels were determined, and the results are shown in Fig. 3. Native SOPC was not found to have any effect on the cellular ATP levels over the concentration range tested, whereas SOPC chlorohydrin clearly caused a dose-dependent depletion of ATP, with $50 \%$ loss at $25 \mu \mathrm{M}$ and almost complete depletion occurring at 100 $\mu \mathrm{M}$ chlorohydrin. The results with SLPC chlorohydrin were similar to those obtained with SOPC, but the effect on cellular ATP was slightly more marked at the higher concentrations. However, the native lipid was observed to cause a small depletion of ATP at 100 and $200 \mu \mathrm{M}$, in contrast to the monounsaturated phospholipid. SAPC chlorohydrin also clearly caused ATP depletion, although the effect was apparently less than that found with the other two phospholipids. However, the conversion of SAPC to chlorohydrins was observed to be incomplete, with on average only about $40 \%$ conversion occurring; thus the effect of this chlorohydrin is actually greater than that of the chlorohydrins of the more saturated lipids. A striking response to the native SAPC was also observed, as the cells showed significant loss of ATP at concentrations of $25 \mu \mathrm{M}$ and above. The responses of U937 cells to all the phospholipid chlorohydrins were almost identical to those observed with HL60 cells (data not shown).

Fig. 4 shows the results of an experiment to investigate the timescale of the effects observed with chlorohydrins. U937 cells were treated with $100 \mu \mathrm{M}$ SOPC chlorohydrin and monitored at intervals over a timecourse of $24 \mathrm{~h}$. It can be seen that chlorohydrin treatment caused very little loss of ATP over the first $4 \mathrm{~h}$ of the incubation, whereas at 6-8 $\mathrm{h}$ a small decrease in [ATP] was apparent, and at 22 and $24 \mathrm{~h}$ there was substantial ATP depletion.

Experiments were also carried out on U937 cells with HNE and SOPC chlorohydrin in medium containing only $0.5 \%$ foetal calf serum, to determine whether this increased the sensitivity of the cells to these compounds, but there was not found to be a significant difference between the dose-dependent re-

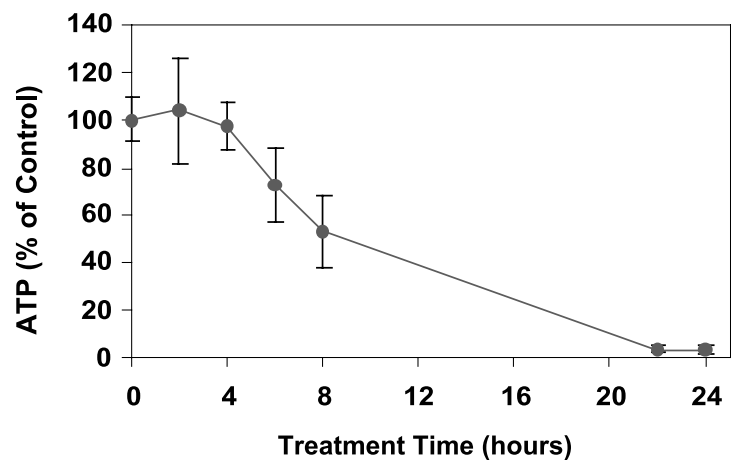

Fig. 4. Time dependence of ATP depletion by SOPC chlorohydrin. U937 cells were incubated with $100 \mu \mathrm{M}$ SOPC chlorohydrin for the timecourse shown, and at each timepoint the intracellular ATP level was determined by bioluminescence as described in Fig. 1. The data are the average of four separate experiments each carried out in triplicate, and the error bars correspond to 1 S.D.
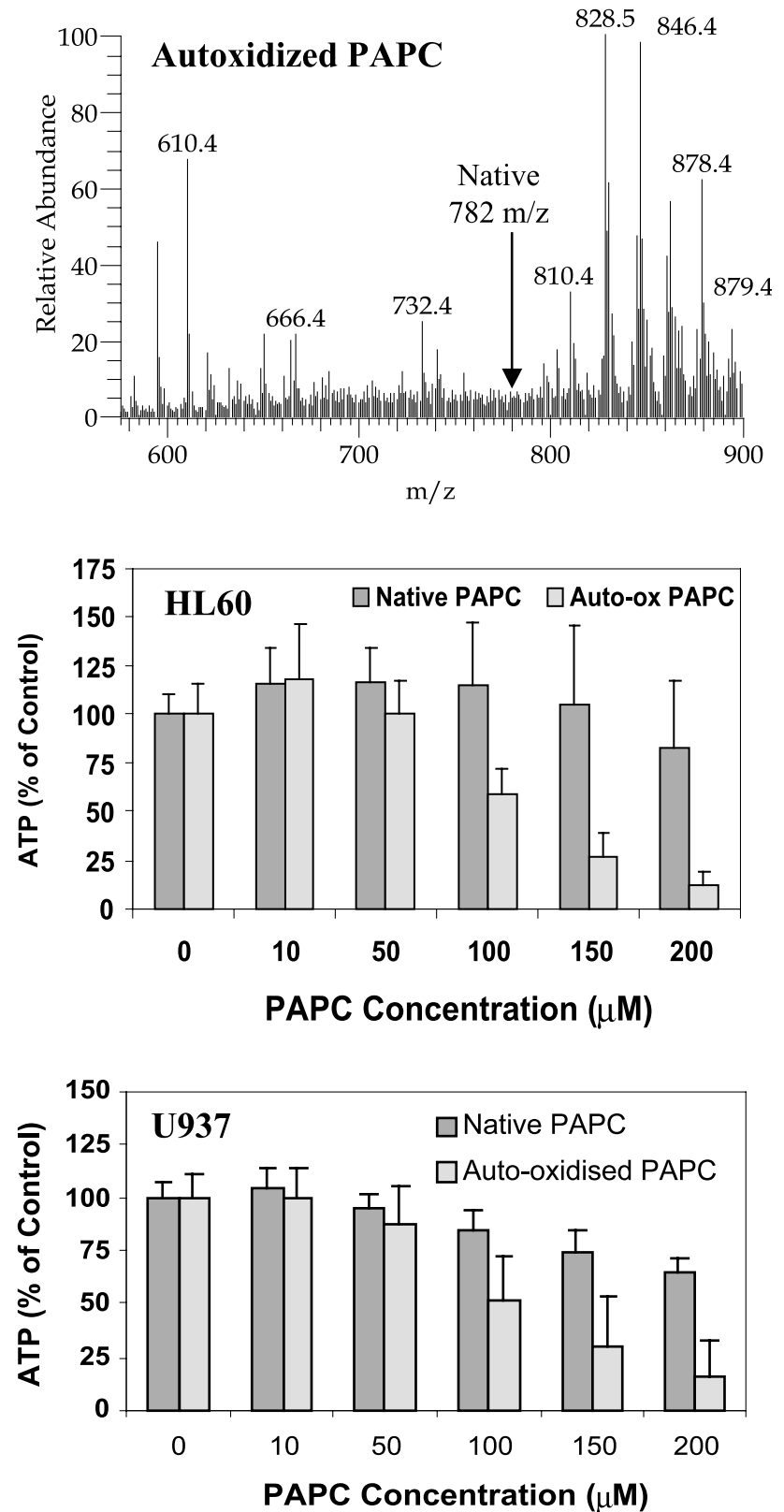

Fig. 5. The effect of autoxidised PAPC on ATP levels in HL60 and U937 cells. The autoxidation of PAPC and product composition were determined by ESMS (top). The native PAPC at $782 \mathrm{~m} / \mathrm{z}$ has been converted to oxidised derivatives $(810,828,846,860$, and 878 $\mathrm{m} / \mathrm{z}$ ) and chain-shortened derivatives at 594 and $610 \mathrm{~m} / \mathrm{z}$. HL60 cells (middle) and U937 cells (bottom) were incubated for $24 \mathrm{~h}$ in RPMI-1640 medium containing the autoxidised PAPC mixture at the concentrations indicated in the graphs, and subsequently the ATP level was determined as described in Fig. 1. With each cell type the effect of native (unoxidised) PAPC was monitored for comparison. The data are the average of three separate experiments each carried out in triplicate, and the error bars correspond to 1 S.D.

sponse at $10 \%$ and $0.5 \%$ serum, for either of the treatments (data not shown).

It has previously been found that a number of esterified oxidation products of PAPC have bioactive effects such as the induction of monocyte-endothelial binding [16,17]. These compounds have been observed in the arterial vessels of hypercholestaemic rabbits, and can be formed in vitro by the 

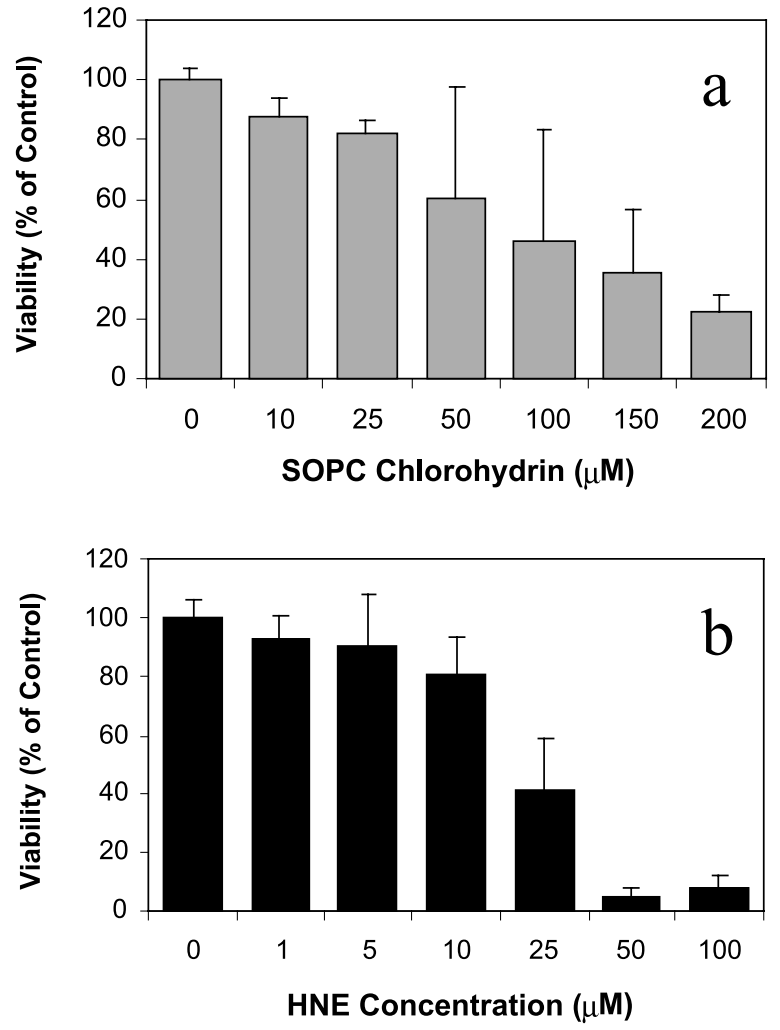

Fig. 6. The effect of SOPC chlorohydrin and HNE on cell viability determined by the MTT assay. U937 cells $\left(1 \times 10^{5}\right.$ cells/well in a 96well plate) were incubated with SOPC chlorohydrin at concentrations of 10-200 $\mu \mathrm{M}$ (a) and HNE at concentrations of $1-100 \mu \mathrm{M}$ (b) for $24 \mathrm{~h}$. The cells were incubated with MTT reagent $(0.5 \mathrm{mg} /$ $\mathrm{ml}$ ) for $90 \mathrm{~min}$ before centrifuging and resuspending in $3: 1$ DMSO:isopropanol. The absorbance was read at $540 \mathrm{~nm}$ in a platereader, and the data are presented as a comparison with control cell viability. The data are the average of four separate experiments each carried out in triplicate, and the error bars correspond to 1 S.D.

autoxidation of PAPC. Analogous experiments were therefore also carried out with autoxidised PAPC to allow comparison of the phospholipid chlorohydrins with other oxidised phospholipids of established bioactivity. The autoxidised PAPC was analysed by ESMS, and showed a very comparable profile of oxidation products to that which was observed to have bioactive effects in previous studies. The autoxidised PAPC mixture was found to cause loss of ATP at concentrations of $100 \mu \mathrm{M}$ and above, both with HL60 and U937 cells (Fig. 5). A small ATP depletion was also observed with the native PAPC, especially in U937 cells.

To investigate whether the changes in cytosolic ATP were related to changes in cell viability, experiments were also carried out using the MTT assay as an alternative method for measuring viable cells. Fig. 6 shows the effect of SOPC chlorohydrin and HNE on U937 cell viability according to this assay. It can be seen that the SOPC chlorohydrin (Fig. 6a) caused a dose-dependent loss of viability, with concentrations of $25 \mu \mathrm{M}$ causing substantial loss of viability and only $20 \%$ viability remaining at $200 \mu \mathrm{M}$. With this assay it was also apparent that HNE was more toxic than the chlorohydrin, with substantial loss of viability at $25 \mu \mathrm{M}$, and fewer than $10 \%$ of viable cells remaining after treatments with $50 \mu \mathrm{M}$ HNE.

\section{Discussion}

The results presented clearly show that phosphatidylcholine chlorohydrins cause the depletion of cytosolic ATP in human myeloid cells. Surprisingly, there was not a great difference between the effects of the three chlorohydrins tested; they caused approximately a $50 \%$ loss of ATP at $25 \mu \mathrm{M}$, and almost complete depletion at $100 \mu \mathrm{M}$. There was evidence of some increase in effect with increasing unsaturation, corresponding to increasing substitution, but the extent of chlorohydrin substitution did not affect the ATP depletion as much as had been expected.

In terms of a comparison with other lipid oxidation products, the chlorohydrins caused more ATP depletion than the alkenals tested (hexanal and trans-2-nonenal), but were somewhat less effective than HNE, which is known to be one of the most deleterious aldehyde products of lipid peroxidation. The effect of HNE on the two cell lines tested, HL60 and U937, was in general agreement with previous reports that HNE concentrations of $1-100 \mu \mathrm{M}$ cause various effects including toxicity, apoptosis, chemotaxis and differentiation in a variety of cells [18-20]. It was thought that the presence of foetal calf serum during the incubation might have decreased the effect of the HNE, although experiments with a reduced level of foetal calf serum $(0.5 \%)$ were not found to increase the ATP depletion. Possibly even a small amount of foetal calf serum can inactivate HNE, but incubation of the mammalian cells without serum over this timecourse was not feasible. The effects of the phospholipid chlorohydrins were also compared to that of autoxidised PAPC, which has previously been used as a model for the bioactive lipid oxidation products found in minimally modified LDL [17]. Each of the individual chlorohydrins caused more ATP depletion in the cells tested than the oxidised PAPC mixture; this may reflect the fact that more than a dozen different products are present in this treatment, not all of which may be toxic, although three products identified as having high bioactivity in previous studies were substantial components of the mixture. Thus it is possible that individual components of the oxidised PAPC have a similar ability to deplete ATP to the chlorohydrins, but in combination as a model for oxLDL, the depletion induced was lower.

The CellTitre-GloTM Luminescence assay is marketed as a sensitive method for measuring the viability of mammalian cells, and its application has been reported previously in several studies [15,21,22]. While small fluctuations in cellular ATP levels may occur in viable cells, severe depletion of ATP to less than $5 \%$ of normal values is likely to correspond to a substantial loss of cell viability. To test this, experiments were also carried out using the MTT assay as an alternative and well established method for monitoring viability, and these showed that SOPC chlorohydrin did cause loss of cell viability (i.e. it was toxic to the cells) at comparable concentrations to those that caused depletion of cellular ATP. Similarly, HNE treatment of the cells also caused loss of viability, although the toxicity was somewhat lower than expected; this may be due to the presence of foetal calf serum as mentioned earlier. In both cases, the loss of ATP was more severe than the loss of viability at any one treatment concentration. Thus it can be seen that ATP depletion correlates reasonably, but not exactly, with loss of viability measured by a conventional method. It is possible that depletion of ATP is an earlier event 
than loss of dehydrogenase function in the process of cell death.

However, neither of these methods distinguishes between apoptosis and necrosis, as both types of cell death involve decreases in cytosolic ATP levels and loss of cell function. In previous studies of oleic acid chlorohydrins it has been reported that they result in membrane damage in erythrocytes [23] and in endothelial cells [13], and that a necrotic mechanism is responsible for the loss of viability. In this study, no significant uptake of trypan blue was observed following chlorohydrin treatment, but as trypan blue has been reported to be considerably less sensitive than ATP bioluminescence in determining cell viability [21], it cannot be concluded that no loss of membrane integrity occurred. On the other hand, the relatively long timescale of ATP depletion suggests that the toxicity of phospholipid chlorohydrins may involve a more complex process than direct incorporation into and disruption of the membrane. It is also possible that the depletion of cellular ATP represents an early event in the process of toxicity, and that membrane disruption due to necrotic cell death might occur at a later stage. It was found that the toxicity of SOPC chlorohydrin measured by the MTT assay was somewhat lower than that reported previously for oleic acid chlorohydrin [13], taking into account the difference in incubation times and the method of assessment of viability.

An interesting point noted was the increasing effect of the native phosphatidylcholines with increasing unsaturation of the fatty acyl chain; a substantial ATP depletion was observed with the polyunsaturated SAPC. Reports in the literature vary considerably with regard to the toxicity of unmodified fatty acids and phospholipids: there have been reports that SAPC had no toxicity to tumour cell lines [24], arachidonic acid causes apoptosis [25], and polyunsaturated fatty acids have selective cytotoxic and cytostatic effects [26]. However, in view of the fact that the cells tested are of myeloid lineage, it is probable that the effect observed is due to oxidation of the phospholipid by the cells to give a toxic product, as has been observed in similar situations for LDL incubated with various cell types [27].

Our results show that intact phospholipid chlorohydrins, which could be formed from LDL phospholipids in atherosclerotic plaques, cause substantial depletion of ATP and loss of viability in cells of a myeloid lineage, such as monocytes and macrophages which are known to be present in plaques. Such effects could contribute to the formation of the necrotic core in advanced lesions.

Acknowledgements: We would like to thank the following for financial support: Tenovus-Scotland, University of Strathclyde Research and Development Fund, and the Glaxo-Jack Endowment.

\section{References}

[1] Ross, R. (1993) Nature 362, 801-809.

[2] Witztum, J.L. and Steinberg, D. (1991) J. Clin. Invest. 88, 17851792.

[3] Chisolm, G.M. and Steinberg, D. (2000) Free Radic. Biol. Med. 28, 1815-1826.

[4] Chisolm, G.M. and Chai, Y.-C. (2000) Free Radic. Biol. Med. 28, 1697-1707.

[5] Comporti, M. (1993) Mol. Aspects Med. 14, 199-207.

[6] Poli, G. and Schaur, R.J. (2000) IUBMB Life 50, 315-321.

[7] Shultz, J. and Kalminker, K. (1962) Arch. Biochem. Biophys. 96, 465-467.

[8] Daugherty, A., Rateri, D.L., Dunn, J.L. and Heinecke, J.W. (1994) J. Clin. Invest. 94, 437-444.

[9] Hazell, L.J., Arnold, L., Flowers, D., Waeg, G., Malle, E. and Stocker, R. (1996) J. Clin. Invest. 97, 1535-1544.

[10] Hazen, S.L. and Heinecke, J.W. (1997) J. Clin. Invest. 99, 2075 2081.

[11] Woenckhaus, C., Kaufmann, A., Bussfeld, D., Gemsa, D., Sprenger, H. and Groene, H.-J. (1998) Clin. Immunol. Immunopathol. 86, 27-33.

[12] Winterbourn, C.C., van den Berg, J.J.M., Roitman, E. and Kuypers, F.A. (1992) Arch. Biochem. Biophys. 296, 547-555.

[13] Vissers, M.C.M., Carr, A.C. and Winterbourn, C.C. (2001) Redox Rep. 6, 49-55.

[14] Jerlich, A., Pitt, A.R., Schaur, R.J. and Spickett, C.M. (2000) Free Radic. Biol. Med. 28, 673-682.

[15] Petty, R.D., Sutherland, L.A., Hunter, E.M. and Cree, I.A. (1995) J. Biolumin. Chemilumin. 10, 29-34.

[16] Watson, A.D., Leitinger, N., Navab, M., Faull, K.F., Hörkkö, S., Witztum, J.L., Palinski, W., Schwenke, D., Salomon, R.G., Sha, W., Subbanagounder, G., Fogelman, A.M. and Berliner, J.A. (1997) J. Biol. Chem. 272, 13597-13607.

[17] Watson, A.D., Subbanagounder, G., Welsbie, D.S., Faull, K.F., Navab, M., Jung, M.E., Fogelman, A.M. and Berliner, J.A. (1999) J. Biol. Chem. 274, 24787-24798.

[18] Muller, K., Hardwick, S.J., Marchant, C.E., Law, N.S., Waeg, G., Esterbauer, H., Carpentar, K.L. and Mitchinson, M.J. (1996) FEBS Lett. 388, 165-168.

[19] Barrera, G., Di Mauro, C., Muraca, R., Ferrero, D., Cavalli, G., Fazio, V.M., Paradisi, L. and Dianzani, M.U. (1991) Exp. Cell Res. 197, 148-152.

[20] Cheng, J.Z., Singhal, S.S., Sharma, A., Saini, M., Yang, Y., Awasthi, S., Zimniak, P. and Awasthi, Y.C. (2001) Arch. Biochem. Biophys. 392, 197-207.

[21] Kuzmits, R., Rumpold, H., Muller, M.M. and Schop, G. (1986) J. Clin. Chem. Clin. Biochem. 24, 293-298.

[22] Kanga, L., Gronroos, M. and Nieminen, A.L. (1984) Med. Biol. 62, 338-343.

[23] Carr, A.C., Vissers, M.C., Domigan, N.M. and Winterbourn, C.C. (1997) Redox Rep. 3, 263-271.

[24] Kafrawy, O., Zerouga, M., Stillwell, W. and Jenski, L.J. (1998) Cancer Lett. 132, 23-29.

[25] Scorrano, L., Penzo, D., Petronilli, V., Pagano, F. and Bernardi, P. (2001) J. Biol. Chem. 276, 12035-12040.

[26] Cantrill, R.C., Ells, G.W., DeMarco, A.C. and Horrobin, D.F. (1997) Adv. Exp. Med. Biol. 400A, 539-544.

[27] Morel, D.W., DiCorleto, P.E. and Chisolm, G.M. (1984) Arteriosclerosis $4,357-364$. 